\title{
Emergence of a Self-Organized Dynamic Fishery Sector: Application to Simulation of the Small- Scale Fresh Fish Supply Chain in Senegal.
}

\author{
Jean Le Fur \\ Institut de Recherche pour le Développement - Centre de Recherche Halieutique \\ Méditerranéenne et Tropicale (CRH) - Av. Jean Monnet, BP171, 34203 Sète Ce- \\ dex, France - lefur@ird.fr
}

\section{Introduction}

The artisanal fishery sector in Senegal is a complex system of fishermen and fish traders acting in close interaction. Indeed, in the overall marine fishery sector, several ethnic groups with different behaviors target more than a hundred fish species using nineteen types of fishing gear (Laloë and Samba 1990). Once fishermen land their catches, another complex set of fish traders is in charge of the food product distribution (Chaboud 1985). Seafood can then be sold on the beach, processed, transported to the various markets of the country or brought to Dakar, the capital, for export. The overall dynamics observed are the result of composite biological, technological and socio-economic interactions.

A historical review of this fishery sub-sector (Chauveau and Samba 1990) pointed out that management changes introduced in the small-scale fishery more often than not led to unexpected effects. Indeed, some management measures introduced for a given purpose often led to undesirable consequences on other parts of the exploitation that were not concerned by the given measure.

The system appears to be an archetype of complexity. From a management perspective, explanations may be sought for the conditions under which such a complex sector achieves organization and stability, despite the multiple dependencies existing between the different components. Answering such a question could help to better depict the possible derived consequences of a given management measure introduced into this sector.

Studies and models on trade/market/price systems of self-organization and equilibrium are usually detailed insights which consider one or a few aspects of the market or chain dynamics such as price fixing (Gale 1987, Donangelo et al. 2000, Calvó-Armengol 2003, Zhu 2004), trade-offs and negotiation mechanisms (Faratin et al. 2002, Lemke 2004), interaction schemes and the network configuration of markets (Guriev and Shakhova 1996, Iori 2002, Vriend 2004), decentralization effects (Calvó-Armengol 2003), multiple levels of exchange such as in sup- 
ply chain models (Kaihara 2001, Dangelmaier et al. 2002), and the interaction between prices and consumption (Nagel et al. 2004).

In a world like the fishery sector, a given market can be considered as a local phenomenon embedded and connected in a variety of others, all of which together constitute the overall sector dynamics. This means that all of the cited aspects of the dynamics may be of importance and should simultaneously play a role in the overall dynamics.

Moreover, the studies presented are usually described using abstract situations where localization and distances are not considered. In the real world of the fishery trade sector, transport costs are clearly a significant part of the fish price fixing as well as choices for a given place or another constitute key factors of the supply and demand dynamics. Furthermore, the resource-harvesting dynamics should clearly influence the dynamics of supply and fish market prices.

Again, these multiple factors all intervene simultaneously at different levels and scales. The question then remains of the ability and means for a complex trading sector to converge, in such a context, towards self-organization and exhibit any equilibrium or steady-state.

A multi-agent computer model restricted to the fresh fish supply chain in Senegal has been developed to study this question. The model is based on the representation of the agents' choices, actions and interactions. The multi-agent formalism has been used since it easily permits modeling of decentralized processes as well as studying adaptive or emerging phenomena (Railsback 2001). These latter are indeed felt to be the possible keys for the emergence of self-organization or equilibrium. Moreover, multi-agent formalism looks very suitable for studying systems where negotiation and multi-criteria functions play central roles (Oliveira et al. 1999).

\section{Model presentation}

\section{Outline}

The model is based on a cybernetic (Ashby 1964) perception of the domain. In this approach, the fishery sector is considered as a set of four interconnected networks within which circulate money, fish, human agents and information. These flows may be interconnected at some points where matter can be exchanged (e.g., money exchanged for fish, activity for money). From this viewpoint, looking for a sustainable exploitation of Senegalese resources may consist in maintaining these flows.

These overall dynamics are formalized at a finer scale using a diversified combination of local actions and interactions: The human groups in charge of the exploitation (fishermen, fish traders) constitute the concrete link between biological, technical, economic and social dynamics. The agents are endowed with various 
Emergence of a Self-Organized Dynamic Fishery Sector: Application to Simulation of the Small-Scale Fresh Fish Supply Chain in Senegal. 3

behaviors allowing them to obtain information from their environment, make choices about it and produce several actions. For these agents, the ability to respond to changes in their environment hinges on their ability to choose from one alternative to the other, and their ability to negotiate with other agents.

The combination of the different actions produces flows of fish, currencies, human agents and activity and, finally, the overall dynamics (production, richness) of the fresh fish channel.

\section{Class Structure}

To investigate this composite issue, the object-oriented design of the multiagent model leads to a class hierarchy where each sub-class 'is-a-kind-of' its super-class. The classes that have been retained in the model of the Senegalese exploitation are presented in Figure 1.

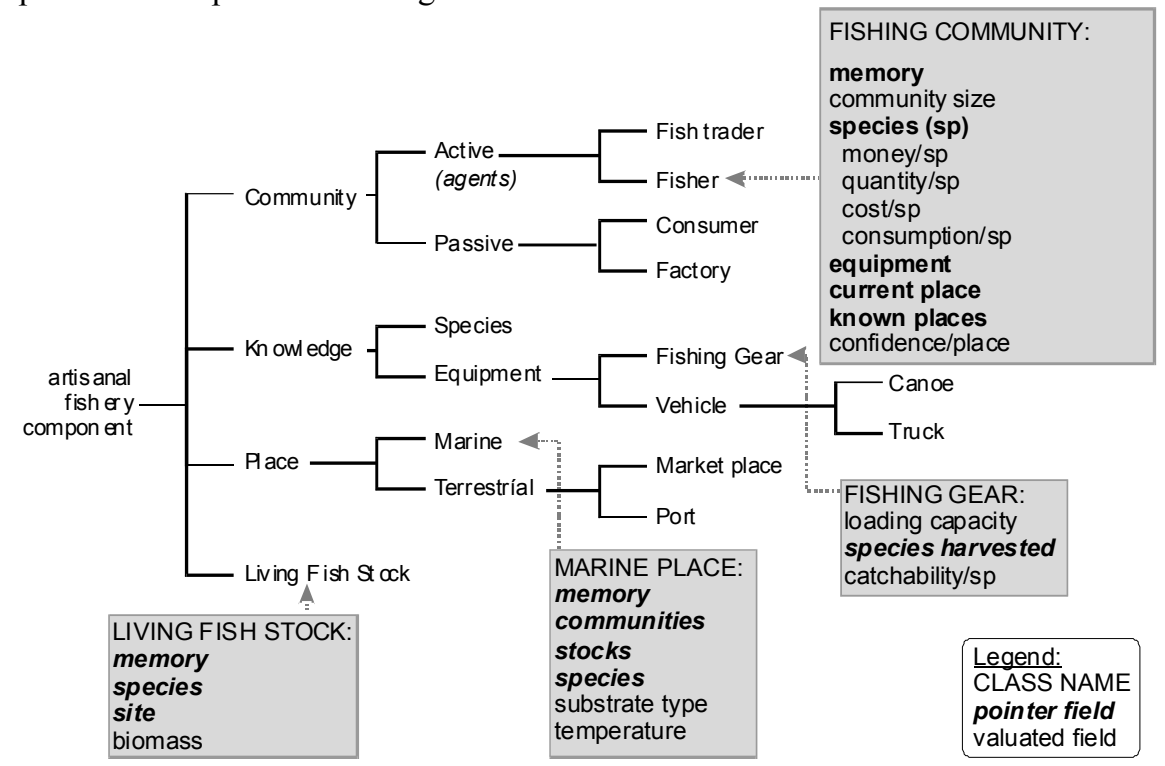

Figure 1: Computer constituents (classes) selected to formalize the domain. Grey boxes show examples of the object characterization for each corresponding class (note: the "memory" field refers to a separate storage class not figured in the hierarchy)

The overall fishery exploitation is composed of four main classes: the communities conducting the various flows, the knowledge they can access for this purpose, the places in which they operate and the living fish stocks they harvest. These major classes are divided into more specialized ones to obtain a sufficient (parsimonious) description of what composes the fishery exploitation. In each of the eleven terminal classes, several objects are differentiated. Each object in a given class is given a set of attributes that are defined by the class to which it be- 
longs (four examples are presented in Figure 1). The value of these objects' attributes document either the relationships with other objects (pointer fields) or specific characteristics (valuated fields).

\section{Functional representation}

Upon this structure a multi-agent formalism, as described in Ferber (1999), has been developed. The Active-Community class contains the active agents (fishermen and fish traders) of the food supply chain. These objects can elaborate information and produce actions through the nesting of messages sending and replies :

In this model for example, if a fishing community needs to know the traders' demand for a given species in a given port, it sends the corresponding message to the port's agent. The port sends the message "species' needs" to each of the fishtraders currently in this place. Each fish trader then conducts an internal evaluation of its requirements for this species. It replies by sending a message back to the port. The port cumulates the answers and after a compilation can reply back to the fishing community.

At a higher level of combination some basic activity of the various agents in the exploitation can be formalized. The example in Figure 2 represents fishermen's actions once they have gone fishing and come back to land their catches:

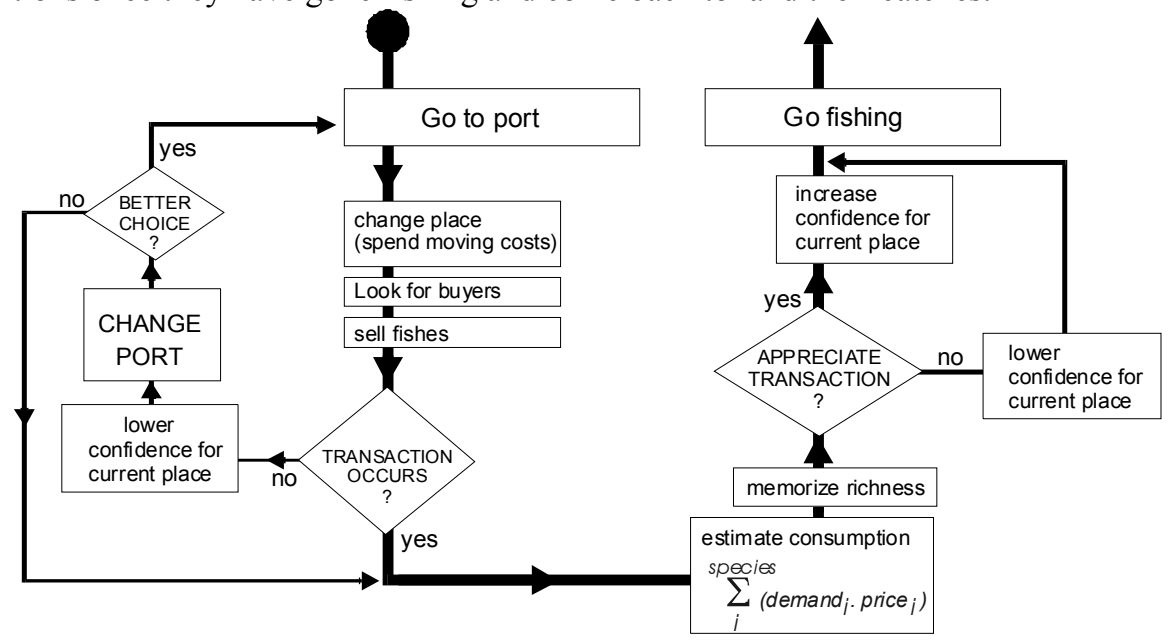

Figure 2: Flow chart of the 'go to port' action performed by a fishing community agent (e.g. after fishing). Each box corresponds to an 'order' (set of messages) sent by the fishing community to itself

Each fisherman agent arriving in a port tries to sell its fish. If it succeeds, it memorizes the results of its action and then stands by. The next time it will have to act, it will choose to go to sea. If the transaction does not succeed, because there are no fish traders for its fish or the negotiation did not succeed, fishermen look for another port (action 'change port') using a decision process sub-model derived 
Emergence of a Self-Organized Dynamic Fishery Sector: Application to Simulation of the Small-Scale Fresh Fish Supply Chain in Senegal.

from Le Fur $(1995,1998)$ : according to the information it can gather from other objects and agents, the community elaborates a set of alternatives to where it can go. For each of these places, it evaluates the opportunity related to several criteria. In this case, the opportunity to go to one port or the other will depend on traders' demand, species prices, transport costs, confidence for one or the other place. After comparing the opportunity for each of the alternatives, whether it finds a better place to sell its fish and then goes to the new port where the whole process starts again, or it does not find a better place, and stands by for the next fishing trip. If, during its standby, fish trader agents happen to arrive in this port, selling may occur.

To account for the whole exploitation activity, four similar processes have been formalized: two for the fishermen agents: 'go fishing' and the 'go to port' just described, and two for the fish traders' agents: 'go to port' and 'go to market'.

At each time step, each active agent, fisherman or fish-trader has to choose from one of its two moves. Going to the same place is allowed as a stand-by. Depending on its stocks (fish, money) and the result of its preceding choices, it goes to a given place whose characteristics conduct it to a specific 'action'. For example, a fisherman arriving at a fishing zone fishes, a fish-trader in a port tries to buy fish, etc. Any action conducted leads to a subsequent 'evaluation' of its result. This evaluation may lead to change or no change in the next action aimed at by the active agent.

\section{Interaction and transaction}

When two communities, a buyer's and a seller's, happen to meet in a given place, negotiation may occur, followed or not by a transaction. A sub-model has been developed to formalize this mechanism.

Transaction sub-model: Since in Senegal, bargaining is the rule for exchange, the transaction sub-model represents selling by private contract between the different communities: at the beginning of the transaction, the selling community (fisherman, fish trader) obtains information from its surroundings, evaluates the cost caused by the previous activity (moving, buying, fishing) and proposes its price. The buyer (fish trader, customer) considers its previous costs or needs and puts forth its own proposition. The final price of the transaction will be a value between the seller's lowest price and the buyer's highest price. In decision theory, given $A$ a set of acts, $E$ the possible states of an environment, the possible consequences $(C)$ can be described through a probability distribution. A rule of thumb (e.g., Charreton and Bourdaire, 1985) establishes the possible mean of this distribution (i.e., final price) as: $1 / 3 \cdot$ [maximum of the distribution + minimum of the distribution + mode]. Following this scheme, the transaction price will be, for example in a port: $1 / 3 \cdot[$ fishermen's price + traders' price + final price in the port during the last transaction concerning this species]. If the final price is acceptable to both partners, the transaction occurs and the price changes in the port. In a given time step, the evolution of the traders' arrival in the port and their successive 
transactions generates the port's fish prices dynamics. These fluctuations will again intervene in the agents' choices. This procedure is duplicated in the market places where transactions occur between fish traders and consumers.

Since the agents may own fish and currencies, their moves lead to the activation of the various flows constituting the exploitation. Moreover, depending on the place where an agent operates, it can come into interaction with other agents and decide whether or not to exchange matter (work into fish, fish into currency, etc.). In this way, the accuracy of the moves and of the interactions will be a condition for an accurate subsequent action.

\section{Simulation process}

Simulation scenarios are built using data available in the literature (Chaboud 1985, Chaboud and Kébé 1990, CRODT 1989, 1990). The whole Senegalese exploitation has first been instantiated and led to a scenario with a system composed of 126 fishing community agents accounting for 3193 fishing teams, 1421 traders agents, 14 markets, 9 ports, 13 fishing zones, 5 fishing gears types, 6 vehicle types and 21 types of fish species. For practical reasons, simulations have been conducted with subsets of this configuration. In this study, the scenario accounts for the North coast of Senegal with only gillnets and lines, 2 ports and 8 markets.

At the beginning of the simulation, active fish traders (trucks) and fishermen (canoes) are positioned on their current places. Each community agent is given 45.000 $\mathrm{CU}$ for 15 days (with $\mathrm{CU}$ : currency unit such as $1 \mathrm{CU}$ approximates to 1000 Senegalese CFA Francs). The simulation then proceeds step by step with one time step equivalent to a fortnight. At each time step the external sources of fluctuation are documented. This consists in making the natural resources produce fish on one side of the system and providing consumers with money and consumption needs on the other side. Each active community is then allowed to produce an action. Depending on their environment, their preceding choices and results, fishermen and fish traders move to one or another type of place, port or market, and try to fish, sell or buy.

At the beginning of a simulation and depending on the initial scenario, the communities introduced into the "virtual exploitation" may not fit with the particular environment simulated. For example, a fisherman with bad information will not go where fish traders are waiting, another may look for unavailable species, a fish trader may go to distant markets and incur high transport costs, etc. Depending on their action some communities may thus lose money. If a community, through its activity happens to lose more than $10.000 \mathrm{CU}$ in the 15 preceding steps, it leaves the fishery. The most indebted agents leave the "virtual exploitation' first and, from time to time, only the fittest communities remain in the exploitation. 
Emergence of a Self-Organized Dynamic Fishery Sector: Application to Simulation of the Small-Scale Fresh Fish Supply Chain in Senegal. 7

\section{Simulation results}

Owing to the structure of the multi-agent system, it is possible to obtain an insight into the various levels of the fishery system dynamics.

- At the finest scale, activities, decision processes, negotiations and transactions between agents can be traced precisely. Traces show diversified choices and actions through time and from one agent to the other. The listing in Figure 3 presents a snapshot of a fishing community during the transaction phase of their activity.

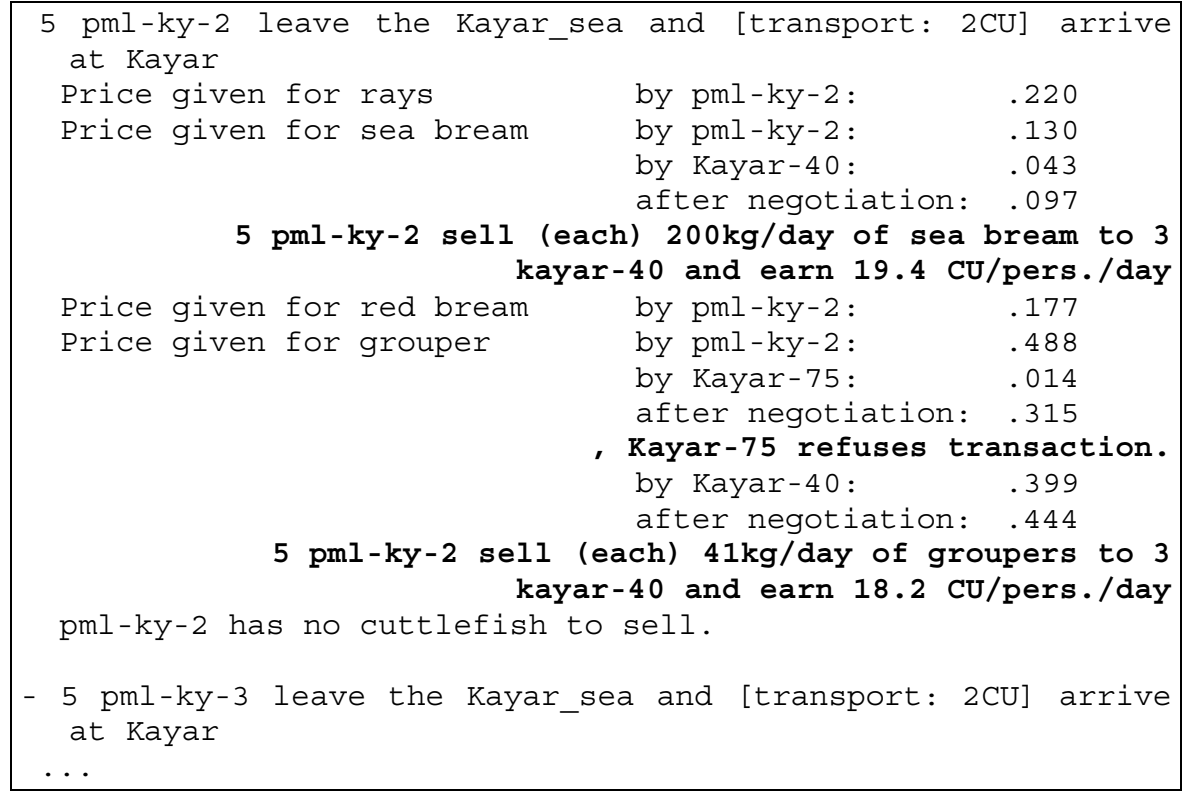

Figure 3: An example of the simulated transactions. At the local scale, the actions performed by the agents are traced by the computer. In this example, information has been filtered to keep the selling task trace only (explanation given in text)

In this example, the fishing community agent named 'pml-ky-2' comes back to 'Kayar' port object after having fished in 'Kayar_sea' marine place object. It tries to sell its 'rays' but no fish trader is interested in this species. Nothing thus happens. The fishermen community then tries to sell its 'sea bream'. Taking into account its previous costs, the quantity owned and the port's price, it proposes a price (.130). The fish traders' agent named 'kayar-40' is interested in buying and makes an offer. After "bargaining" the price is negotiated to .097 and the two communities proceed to the transaction. For the 'red bream' species, fishermen do not find any traders. For the 'grouper' species, the 'kayar-75' traders' agent proposes a very low price (.014). The negotiated price remains too high and the trader refuses the exchange. The former trader's community 'kayar- 40 ' is also interested in the 'grouper' species and here, the negotiation succeeds. At the end of negotia- 
tion, fish traders ask for 'cuttlefish' species but the fishermen community did not target this species. Nevertheless, this may conduct the community to later choose a fishing place to catch this species. Thereafter another fishing community 'pml-ky3 ' arrives at 'Kayar' and the process goes on.

- At a higher scale, local indicators can be studied. For example, from time to time and depending on the moves of the various communities, supply and demand fluctuates from one site to the other and, through negotiations, the species prices change. The example in Figure 4 presents an emerging co-evolution of the grouper species price dynamics in a port and its nearest market.

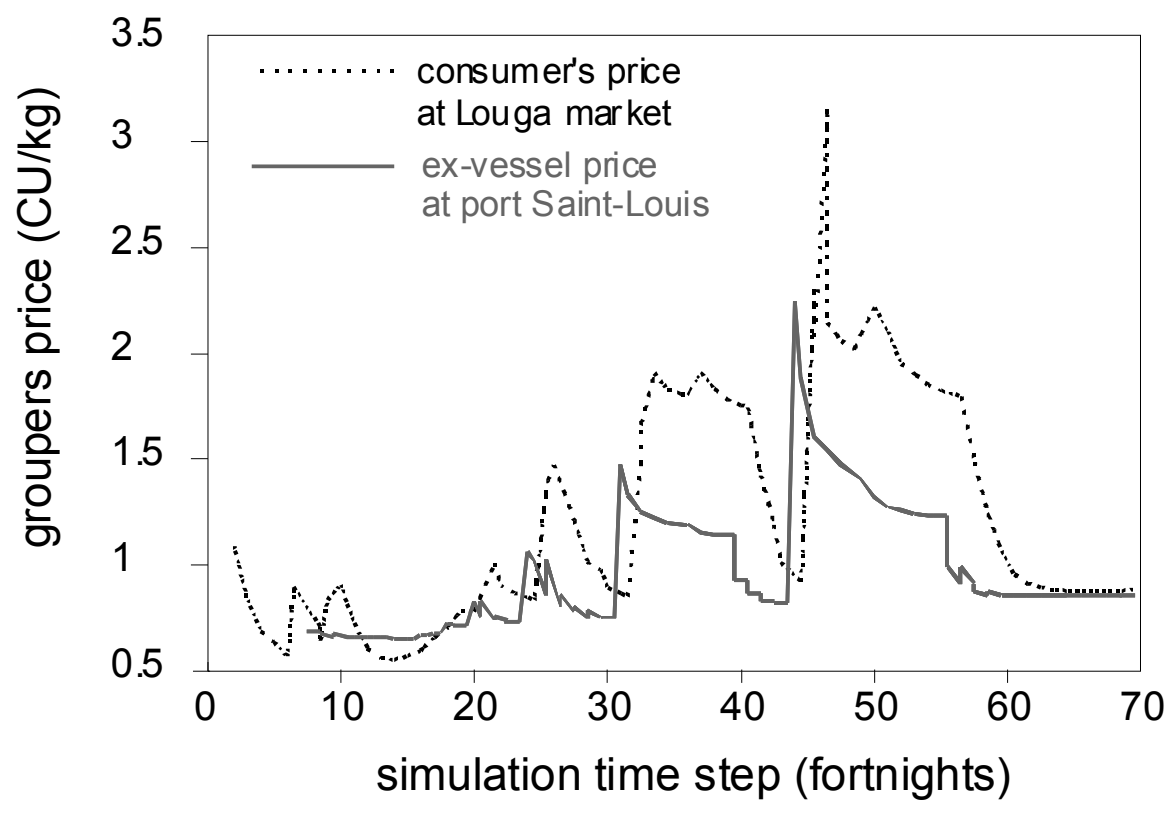

Figure 4: Price changes of the grouper species in two related places (a port and a nearby market). Results from a simulation

Dependencies appear between the two places. The comparison of temporal changes in prices shows higher prices in the market than in the port. Moreover, fluctuations in the port propagate with a delay in the market. The response curve shows a sharp increase followed by a slow price decay. This corresponds to a period of shortage when the prices increase followed by period of over-supply when price falls as new providers/sellers arrive. Some unexplained fluctuations also appear such as the amplification of the prices observed between $t_{20}-t_{50}$ followed by a decrease around $t_{60}$. In the model, since the whole set of ports and markets are interconnected, changes occurring in a given place object (e.g., disaffection for a port or a market) can lead to changes in other places thus causing these indirect, and often difficult to figure out, variations. 
Emergence of a Self-Organized Dynamic Fishery Sector: Application to Simulation of the Small-Scale Fresh Fish Supply Chain in Senegal. 9

- Finally, at the overall scale, various flows can be monitored in the simulation. The example in Figure 5 shows a possible evolution of the simulated fishery.

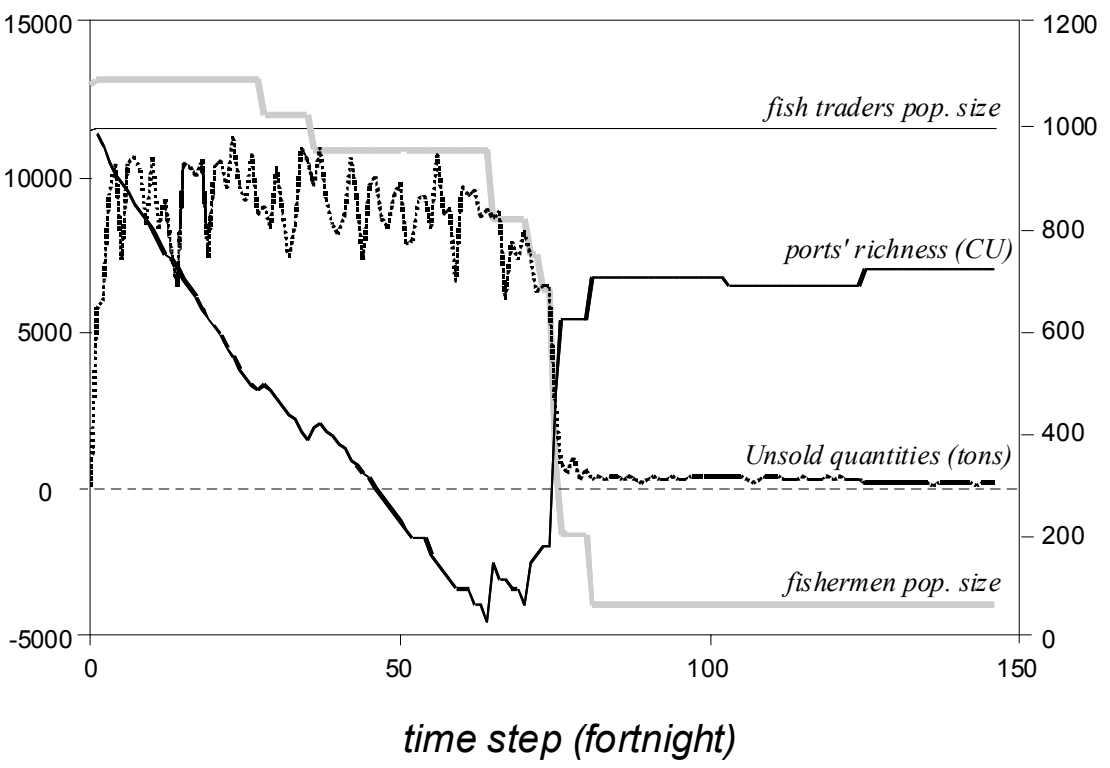

Figure 5: Self-organization of the virtual exploitation (North coast and markets of Senegal with gillnets and lines only). Results from a simulation

At the beginning of the simulation, fish landings are greater than the buying capacity of the fish traders. The unsold quantities are too high and fishermen lose money. The exploitation is indebted overall (port's richness). Through time, fishermen who are not able to support the loss leave the fishery (fishermen population size). The fish traders' number remains stable. In the middle of the simulation, the fisherman number reaches a low level until it is fitted to the trading capacity of the fish traders. The exploitation is, from that time, composed of many fish traders with small buying capacities and a few fishermen communities providing the exact demand. The four dynamics become stationary. The unsold quantities tend to zero; the exploitation richness is positive and stable.

\section{Discussion}

Following the classification by Straškraba (2001), the simulated fishery sector exhibits both self-adaptation (tuning parameters without modifying structure) and self-organization (connecting or disconnecting a diversified set of relationships). 
Some simulations demonstrated the model's sensitivity to the agents' choice criteria, the order in which the agents act or the initial conditions of the simulations. As these factors modify the dynamics, the results of the simulation cannot be closely related to observed real events; they just display a possible situation arising from an approximation of the real context.

The validation of the model is conducted by comparing the activity of the virtual exploitation at each functional level with observed patterns: fishermen go fishing, fish traders arrive in the right market at the right time, the negotiation process is rational and reliable compared to what is known of the bargain process, prices are realistic compared to those observed, related places co-evolve, etc. The simultaneous consistency of the dynamics observed at various levels is a factor that reinforces confidence in the emergent dynamics observed.

\section{Conclusion}

In the course of a simulation, the communities' objectives change depending on their various activities (fishing, selling, moving, buying, consuming). From one objective to another, from one type of community to another and from one environment to another, the decision processes lead to different choices. The resulting sum of the activities modifies the context (i.e., environments) through time and, by feed-back, influences the various evaluations processed by the agents. Even in such a complex multivariate system there exist some combinations for which the system is sustainable.

The agents' diversity and the multiplicity of their local action provide a large degree of freedom to the multi-agent system. This feature can contribute to make sustainable combinations available. Moreover, when associated with a simple process of agent fitness selection, this 'distributed-diversity' feature also provides the ability for the simulated system to converge autonomously towards a correct parameter combination.

\section{References}

Ashby WR (1964) Introduction to Cybernetics. Methuen, New York

Calvó-Armengol A (2003) A decentralized market with trading links. Mathematical Social Sciences 45:83-103

Chaboud C (1985) Le mareyage au Sénégal. CRODT-ISRA, doc Sci 87, 112p

Chaboud C, Kébé M (1990) Commercialisation du poisson de mer dans les régions intérieures du Sénégal (données statistiques). CRODT-ISRA, contrat FAO 695 TCP/SEN/6653(t), septembre 1990, 300p.

Charreton R, Bourdaire J M (1985) La décision économique. Presse universitaire de France ed, Que sais-je?, 1985, ISBN 2-13-039042-0, 125p 
Emergence of a Self-Organized Dynamic Fishery Sector: Application to Simulation of the Small-Scale Fresh Fish Supply Chain in Senegal.

Chauveau JP, Samba A (1990) Un développement sans développeurs ? Historique de la pêche artisanale maritime et des politiques de développement de la pêche au Sénégal. Doc ISRA, série Réflexions et Perspectives, 20p

CRODT (1989) Statistiques de la pêche artisanale maritime sénégalaise en 1987. Arch Centr Rech Océanogr Dakar-Thiaroye, no 175, juillet 1989, 85p

CRODT (1990) Recensements de la pêche artisanale maritime sénégalaise entre Djifère et Saint-Louis mai et septembre 1987. Arch Centr Rech Océanogr Dakar-Thiaroye, no 181, juillet 1990, 49p

Dangelmaier W, Franke H, Pape U (2002) A Multi-Agent-Concept in Supply Chain Management. In: International Manufacturing Leaders Forum. Adelaide, 8 - 10 February 2002

Donangelo R, Hansen A, Sneppen K, Souza S (2000) Modelling an imperfect market. Physica A 283:469-478

Faratin P, Sierra C, Jennings NR (2002) Using similarity criteria to make issue trade-offs in automated negociations. Artificial Intelligence 142:205-237

Ferber J (1999) Multi-agent systems - An introduction to distributed artificial intelligence. Addison-Wesley ed, Arlow, Great Britain, 509 p

Gale D (1987) Limit theorems for markets with sequential bargaining. J Economic Theory 43(1):20-54

Guriev S, Shakhova M (1996) Self-Organization of Trade Networks in an Economy with Imperfect Infrastructure. In Schweitzer F (ed) Self-Organization of Complex Structures: From Individual to Collective Dynamics. Gordon and Breach Scientific Publishers, London Iori G (2002) A microsimulation of traders activity in the stock market: the role of heterogeneity, agents' interactions and trade fictions. J Econ Behavior \& Organisation 49:269-285 Kaihara T (2001) Supply chain management with market economics. Int J Production Economics 73:5-14

Laloë F, Samba A (1990) La pêche artisanale au Sénégal: ressource et stratégies de pêche. Etude et Thèses, Paris, Orstom ed, 395p

Le Fur J (1995) Modeling adaptive fishery activities facing fluctuating environments: an artificial intelligence approach. AI Appl Agric Nat Res Environ Sci, 9(1): 85-97

Le Fur J (1998) Modeling fishery activity facing change: Application to the Senegalese artisanal exploitation system. In : Durand MH, Cury P, Mendelssohn R, Roy C, Bakun A and D Pauly (sci eds) Global vs local changes. Orstom coll Colloques et séminaires, Paris, pp 481-502

Lemke RJ (2004) Dynamic bargaining with action-dependent valuations. J Econom Dynamics \& Control 28:1847-1875

Nagel K, Shubik M, Strauss M (2004) The importance of timescales: simple models for economic markets. Physica A 340:668-677

Oliveira E, Fisher K, Stepankova O (1999) Multi-agent systems: which research for which applications. Robotics and Autonomous Systems 27:91-106

Railsback SF (2001) Concepts from complex adaptive systems as a framework for individual-based modeling. Ecol Modelling 139:47-62

Straškraba M (2001) Natural control mechanisms in models of aquatic ecosystems. Ecol Modelling 140:195-205

Vriend N (2004) ACE models of market organization. Rev Econ Industrielle 107:63-74

Zhu J (2004) A buyer-seller game model for selection and negotiation of purchasing bids: extension and new models. European J Operational Research 154:150-156. 